\title{
Formação às avessas: problematizando a simetria invertida na educação continuada de professores'
}

\author{
Adolfo Samuel de Oliveira" \\ Belmira Oliveira Bueno"
}

\section{Resumo}

0 trabalho busca problematizar a implementação do modelo de formação docente prescrito pela legislação educacional brasileira, por meio da análise de um Programa de Educação Continuada, o PEC Formação Universitária Municípios, realizado no Estado de São Paulo entre 2003 e 2004. A pesquisa é de natureza qualitativa. Contou com observações em contextos de ensino on-line e off-line, durante 18 meses, e coleta de materiais de natureza diversa: documentos oficiais, notas de campo, entrevistas, além de trabalhos produzidos pelas alunas-professoras, em especial uma modalidade de trabalho chamada escritas de memórias. 0 marco teórico fundamenta-se na teoria do habitus de Bourdieu e nas contribuições de seus críticos contemporâneos. Ao investigar os processos formativos inerentes à condição de aluna das docentes, intenta-se analisar as relações entre as situações de aprendizagem observadas ao longo do desenvolvimento do Programa e o modo como foram apropriadas pelas professoras. As análises desenvolvidas permitem afırmar que muitas das reflexões feitas pelas professoras, quando na situação de alunas, tiveram origem em um processo de aprendizagem não previsto e até mesmo ignorado pelo Programa. Esse processo, aqui denominado formação às avessas, colocou em causa o princípio da simetria invertida pelo qual o Programa de Educação Continuada de Formação de Professores (PEC) se orientou e, por conseguinte, alguns dos fundamentos pedagógicos do modelo em análise.

\section{Palavras-chave}

I- Uma primeira versão deste texto foi apresentada na $32^{\text {a }}$ Reunião da ANPEd, no GT de Sociologia da Educação. A pesquisa contou com o suporte da Coordenação de Aperfeiçoamento de Pessoal de Nível Superior (CAPES) e do Conselho Nacional de Desenvolvimento Científico e Tecnológico (CNPq), por meio de bolsas, e com 0 financiamento da FAPESP.

II- Universidade de São Paulo, São Paulo, SP, Brasil.

Contatos: adolfoso@usp.br; bbueno@usp.br
Modelo de formação docente - Simetria invertida - Educação continuada. 


\section{Education in reverse: problematizing inverted symmetry in continuing education for teachers'}

Adolfo Samuel de Oliveiral"

Belmira Oliveira Bueno"

\section{Abstract}

This paper seeks to problematize the implementation of the model of teacher education prescribed by the Brazilian educational legislation, through the analysis of a Continuing Education Program, PEC Formação Universitária Municípios (PEC Higher Education Municipalities), held in São Paulo, from 2003 to 2004. The research is qualitative in nature. It included observations within online and offline teaching contexts over 18 months, and the collection of materials of different natures: official documents, field notes, interviews, and work produced by the student teachers, especially the written memories. The theoretical framework is based on Bourdieu's theory of the habitus and the contributions of his contemporary critics. By investigating the educational processes inherent to the student teachers, we intend to analyze the relations between the learning situations observed throughout the development of the program and how they were appropriated by teachers. The analyzes developed let us state that many of the reflections made by the teachers, in the position of students, originated from a learning process that was unexpected and even ignored by the program. In this work, this process was called educational work in reverse, and put into question the principle of inverted symmetry, which guided PEC, and therefore some of the educational fundamentals of the model under consideration.

\section{Keywords}

Model of teacher education - Inverted symmetry - Continuing education.

I- $A$ first version of this paper was presented at the 32nd Meeting of ANPEd at Sociology of Education WG. The research was supported by CAPES and CNPq through grants and funding from FAPESP.

II- Universidade de São Paulo, São Paulo, SP, Brasil.

Contact:adolfoso@usp.br; bbueno@usp.br 
A preparação para o exercício profissional da docência, levada a efeito nos cursos de licenciatura do país, deve ser orientada, segundo as Diretrizes Curriculares Nacionais para a Formação de Professores da Educação Básica (DCNFP) (BRASIL, 2002), por três princípios: as competências como eixo organizador do curso, a pesquisa enquanto matriz de conhecimentos sobre os processos de ensino e de aprendizagem e a coerência entre a formação oferecida e a prática esperada do futuro professor, cujo pressuposto basilar é a simetria invertida. Esta, pelo fato de o futuro professor ser preparado em um lugar similar àquele em que irá atuar, demanda que haja coerência entre o que é experienciado pelo aluno durante a formação e o que se espera de sua atuação como docente (MELLO, 2000). A partir dessa ótica, o formando deve adquirir no curso de licenciatura, entre outros recursos, tanto as competências requisitadas para o exercício da docência quanto as que seus alunos deverão dominar quando concluírem a educação básica. Tendo em vista esse modelo de formação docente, o presente trabalho objetiva, a partir de um enfoque sociológico, problematizar como se deu a implementação de tais princípios, mais precisamente a relação entre as competências e a simetria invertida, no PEC Formação Universitária, ${ }^{1}$ e examinar as implicações dessa concepção para a formação oferecida às alunasprofessoras desse Programa. ${ }^{2}$

No decorrer do curso, notou-se que a condição de aluna suscitou nas professoras a reflexão a respeito do exercício dos ofícios discente e docente, facultando-lhes compreender vários aspectos das condutas e do processos de aprendizagem de seus alunos, bem como algumas de suas próprias práticas e

1- Programa especial desenvolvido em São Paulo, entre 2001 e 2008, com 0 objetivo de formar, em nível superior, os professores das séries iniciais do ensino fundamental e da educação infantil. A segunda edição, chamada PEC Municípios, constituiu-se no referente empírico da pesquisa e será detalhada adiante.

2- Considerando que a esmagadora maioria dos alunos do curso era formada por mulheres, optou-se por utilizar no texto o gênero feminino. No caso dos tutores, manter-se-á o masculino genérico, já que a composição entre homens e mulheres era mais equilibrada. representações enquanto docentes, sobretudo no que diz respeito às atitudes em relação a seus alunos e a certas atividades propostas em aula. Como muitas dessas reflexões surgiram a partir de determinadas interações com o professortutor (cuja presença se dava diariamente com as professoras, ao modo de um professor polivalente) e de certas experiências formativas, notadamente as avaliações, as professoras observavam, e de alguma maneira aprendiam, o que não deveriam fazer em sala de aula, em virtude do baixo ou inadequado potencial formativo das situações de aprendizagem que vivenciavam no Programa. Esse processo formativo, não previsto na proposta do PEC, pautou-se pelo que aqui denominamos simetria invertida às avessas e despertou a atenção para alguns impasses que permeiam a coerência e a consistência demandadas entre o que se faz na formação e o que se presume que ocorrerá no exercício da profissão.

A pesquisa realizada é de natureza qualitativa, mais precisamente um estudo de caso, que teve como objeto de estudo a condição de aluno do professor nos cursos de educação continuada (OLIVEIRA, 2009). Os dados constituíram-se de documentos oficiais, apostilas, notas de campo (confeccionadas em moldes etnográficos, durante 18 meses), entrevistas semiestruturadas feitas com alunas-professoras e agentes pedagógicos do Programa. Soma-se a esse material um conjunto de memórias, enquanto parte das atividades escritas e obrigatórias realizadas pelas professoras. As notas de campo foram produzidas em contextos de ensino on-line (no laboratório de informática) e off-line (na Semana Presencial), buscando focalizar, sobretudo, as atividades de quatro alunas-professoras que aceitaram participar da investigação (BUENO; OLIVEIRA, 2008). A perspectiva de análise adotada diz respeito aos processos de socialização escolar e se baseia na teoria do habitus de Bourdieu, problematizada por alguns de seus críticos contemporâneos.

0 tratamento das questões ora discutidas requer, primeiramente, que sejam delineadas 
as principais características do PEC Formação Universitária e a maneira como esse programa se apropriou do modelo de formação em voga, em especial das noções de competência e de simetria invertida. Em seguida, analisar-se-á a materialização desses princípios em algumas situações de aprendizagem, a fim de mostrar e compreender a complexidade envolvida em tais processos formativos, bem como as dificuldades inerentes ao planejamento e à execução de cursos de licenciatura nesse formato.

- PEC Formação Universitária: um exemplar dos programas especiais de formação de professores

Referente empírico da investigação, o PEC Formação Universitária Municípios foi realizado em 24 meses, de 2003 a 2004, por meio de uma parceria que envolveu várias instituições de caráter público e privado, quais sejam: a Universidade de São Paulo (USP) e a Pontifícia Universidade Católica de São Paulo (PUCSP); a União Nacional dos Dirigentes Municipais de Educação (UNDIME); a Secretaria de Estado da Educação do Estado de São Paulo (SEESP); a Fundação para o Desenvolvimento da Educação (FDE), a Fundação Carlos Alberto Vanzolini (FCAV) e a Fundação de Apoio à Faculdade de Educação (FAFE), no caso do PEC realizado pela USP. Com o objetivo de dar conta da demanda pela formação em nível superior surgida após a promulgação da Lei $\mathrm{n}^{\circ} 9.394$ de 1996, que estabelece as Diretrizes e Bases da Educação Nacional (LDB), o Programa, definido como um curso de formação continuada de caráter "presencial com forte apoio de mídias interativas" (SÃO PAULO et al., 2003b, p. 13), foi oferecido aos professores efetivos das redes públicas municipais de ensino que ainda não tinham a formação universitária. Tratava-se, então, de uma licenciatura plena para as séries iniciais do ensino fundamental e para a educação infantil. Em termos programáticos, foi concebido em harmonia com as prescrições da Proposta de Diretrizes para a Formação Inicial de Professores da Educação Básica em Nível Superior (PDFIP) (BRASIL, 2000), um dos principais documentos que deu origem e fundamentou as DCNFP, bem como o seu modelo de formação docente. ${ }^{3}$

Do ponto de vista operacional, o PEC foi desenvolvido em prédios dos antigos Centros de Formação e Aperfeiçoamento do Magistério (CEFAM) e em escolas estaduais que dispunham dos equipamentos técnicos necessários. Cada unidade, chamada de polo, foi preparada especialmente para o curso, contando com laboratórios de informática e salas equipadas para videoconferências, teleconferências e atividades de estudo. A carga horária do Programa foi de 3.300 horas, distribuídas entre as seguintes atividades: 1) videoconferências (aulas virtuais, que permitiam a interação em tempo real entre professor e alunos); 2) teleconferências (palestras magnas, geralmente com vários professores especialistas, transmitidas via satélite, fato que possibilitava apenas a interação por e-mail e fax); 3) trabalhos monitorados (atividades que desdobravam os temas abordados nas teles e videoconferências, bem como nas apostilas, sendo feitas em sala de aula, nas sessões off-line e no laboratório de informática, nas sessões on-line; e a cargo do aluno, dentro ou fora da sala de aula, sozinho ou em equipe, nas sessões de suporte); 4) atividades programadas (tarefas previamente determinadas pelo tutor ou orientador para serem realizadas de maneira autônoma pelo aluno); 5) vivências educadoras (trabalho de investigação e reflexão sobre prática pedagógica à luz da teoria); 6) oficinas culturais (atividades que objetivavam enriquecer o repertório cultural dos alunos-professores, a partir dos diferentes usos da leitura, da escrita e das diversas manifestações artísticas); 7) escrita de memórias (relato de tipo autobiográfico, de caráter investigativo e formativo, sobre o processo de formação dos alunos-professores); e 8) desenvolvimento de pesquisa e escrita de

3- 0 projeto pedagógico do PEC Municípios (SÃO PAULO et al., 2003b) é praticamente 0 mesmo da primeira edição do Programa, oferecida pela SEESP em 2001. Porém, apesar de anterior à promulgação das DCNFP (2002), contempla o seu modelo de formação, pois este já estava delineado na referida PDFIP (BRASIL, 2000). 
monografia, trabalho de conclusão de curso (TCC) realizado sob a supervisão de orientador designado pela universidade (SÃO PAULO et al., 2003a). 0 PEC também contou com várias atividades desenvolvidas na chamada Semana Presencial, que consistiam em palestras, mesas-redondas, oficinas, visita a museus etc., ocorridas no campus e em demais órgãos das universidades patrocinadoras do Programa durante o período de férias escolares.

As funções docentes do PEC Formação Universitária estavam divididas entre diferentes agentes pedagógicos: o professor-tutor convivia diariamente com os alunos-professores, era o responsável pela coordenação das atividades do curso e de uma parte da avaliação; o professor-assistente cuidava da supervisão, da correção e da avaliação das atividades on-line e se comunicava com os alunos via internet; o professor-orientador interagia com as professoras tanto em encontros presenciais quanto via e-mail e era responsável pela orientação das vivências educadoras, da escrita de memórias e do trabalho de conclusão de curso, bem como pela correção de tais atividades e das provas do Programa. Além desses, desempenhavam funções docentes os vídeos e os teleconferencistas, responsáveis pelas videoaulas e palestras, respectivamente.

Essa estrutura, uma vez posta em prática, ativou processos antes não presentes ou pouco explicitados em outros modelos de formação e mesmo os que já eram direcionados à educação continuada de professores. Um dos processos que chamou a atenção desde o trabalho de campo refere-se à condição de aluna das professoras, pela vivência simultânea e contínua do duplo papel: docente e discente. Assim, perseguimos a resposta da seguinte indagação: que relevância e potencialidade tal experiência pode ter para a formação dos professores, sobretudo quando, ao realizarem o curso, encontram-se diretamente vinculados ao trabalho em sala de aula? As interpretações expostas a seguir buscam problematizar essa questão, levando em conta a dimensão e a centralidade que a formação continuada adquiriu nas últimas décadas no país, em similaridade com o que vem ocorrendo em vários países, em decorrência das influências e pressões externas.

\section{Socialização, habitus e formação docente}

0 marco teórico da presente investigação é a teoria da prática de Bourdieu (1984, 2004), à luz das contribuições e problematizações oferecidas nessa área por Lahire (2002) e Setton (2002a, 2002b, 2009).

Construída com o fito de equalizar a tensão entre estrutura e ação e superar a dicotomia entre objetivismo e subjetivismo, a teoria da prática de Bourdieu concebe o processo de socialização dos indivíduos como resultado da "dialética da interioridade e da exterioridade, isto é, da interiorização da exterioridade e da exteriorização da interioridade" (BOURDIEU, 1984, p. 60, grifos do autor), que proporciona a incorporação do habitus, considerado um "sistema de disposições duráveis, estruturas estruturadas predispostas a funcionar como estruturas estruturantes, isto é, como princípio gerador e estruturador das práticas e das representações” (BOURDIEU, 1984, p. 60-61), produto das condições materiais e simbólicas de existência de determinada classe ou grupo social.

0 habitus, segundo o sociólogo francês, atua como a mediação entre as relações objetivas e os comportamentos individuais e

[...] torna possível a realização de tarefas infınitamente diferenciadas, graças às transferências analógicas de esquemas, que permitem resolver os problemas da mesma forma. (BOURDIEU, 1984, p. 65)

A prática, nessa perspectiva, é considerada o resultado da relação dialética entre uma situação e um habitus, o que inviabiliza enxergá-la como mera execução das imposições da estrutura objetiva ou como produto das deliberações autônomas do indivíduo. Assim, 
na teoria do sociólogo francês, há uma relação intrínseca entre as posições ocupadas no espaço social ou nos campos (concebidas de maneira relacional), as disposições (ou o habitus) e as tomadas de posição (práticas sociais decorrentes da dialética entre as posições e as disposições) (BOURDIEU, 2004).

Não obstante, como a análise dos processos de formação estudados se deu no plano microssocial e o Programa em foco não apresenta as propriedades necessárias para ser compreendido como um campo (BOURDIEU, 2004), foi preciso adequar os instrumentos de análise a essa escala. Por essa razão, o PEC foi considerado uma configuração, ${ }^{4}$ ou seja, uma rede de interdependência que coloca e condiciona os indivíduos em uma trama ininterrupta de ações, na qual se pressionam mutuamente nos processos de socialização e estabelecem relações com outras configurações, de maneira direta ou mediada, explícita ou difusa, voluntária ou involuntária (ELIAS, 2005; LAHIRE, 1997; SETTON, 2002b). Ao tratar a socialização sob essa ótica, tem-se em vista enfatizar que são os "seres sociais que, nas relações de interdependência e em situações singulares, fazem circular ou não, podem 'transmitir' ou não, as suas propriedades sociais" (LAHIRE, 1997, p. 32-33), em especial quando se trata do capital cultural e do capital escolar.

Nesse sentido, a investigação das práticas, das representações e dos processos formativos dos sujeitos da pesquisa foi pensada a partir das posições que ocupam nas redes de interdependência de que participam, em relação dialética com seus recursos e habitus. Este é entendido como um conjunto de disposições - produto não só das socializações passadas, mas também em construção, em virtude dos estímulos a que está submetido -, cujas disposições (esquemas de pensamento e ação), que tendem a ser acionadas de acordo

4- Elias $(1994,2005)$ concebe a configuração como uma rede de interdependência formada por pessoas mutuamente orientadas e dependentes entre si, em virtude das necessidades recíprocas socialmente geradas, que pode assumir várias formas, tais como famílias, escolas, cidades e até Estados nacionais. com seu contexto de produção e atualização, predispõem o indivíduo a perceber, sentir, apreciar e agir sem obedecer unicamente à memória incorporada e não-consciente, o que o habilita a dar sentido às suas experiências e a recorrer a lógicas reflexivas de ação (BOURDIEU, 1984; SETTON, 2002a, 2007).

Com base nesse quadro conceitual, admite-se a possibilidade de utilizar o conceito de habitus para compreender os indivíduos singulares no plano microssocial, no contexto das sociedades contemporâneas, concebendo a formação docente como um processo de construção e reestruturação tanto dos esquemas de ação ou disposições do habitus quanto dos conhecimentos do indivíduo (PERRENOUD, 2002). Isso torna a formação docente também um processo de autoformação, pois a socialização, enquanto uma forma de educação, leva em conta tanto a aprendizagem e a interiorização de referências sociais quanto a autoconstituição do sujeito e a ressignificação dos conhecimentos, pela mediação do outro (SETTON, 2007). Tal pressuposto deve ser levado em conta, mais ainda quando se trata da formação de adultos, na qual não se pode desconsiderar o papel central da experiência. Experiência que, por ser objeto de reflexão, acaba por fazer do adulto pedagogo de si mesmo, pois, conforme postulado por Dominicé (1992, p. 167), “o saber sobre a formação provém da própria reflexão daqueles que se formam”.

\section{Simetria invertida e competências no PEC Formação Universitária}

Seguindo um movimento internacional do período, a reforma educacional iniciada no Brasil nos anos 1990, cujo marco é a LDB, fez das competências o eixo que estrutura tanto a educação básica quanto a formação docente (inicial e continuada). Segundo Mello (2000, p. 102), uma das mentoras de várias experiências que se estruturaram a partir de então no campo da formação docente, 
É imprescindível que o professor que se prepara para lecionar na educação básica demonstre que desenvolveu ou tenha oportunidade de desenvolver, de modo sólido e pleno, as competências previstas para os egressos da educação básica, tal como estabelecidos nos artigos 22, 27, 32, 35 e 36 da LDB e nas diretrizes curriculares nacionais da educação básica. Isso é condição indispensável para qualificá-lo como capaz de lecionar na educação infantil, no ensino fundamental ou no ensino médio.

De acordo com a autora, as competências, nesse modelo de formação, não podem ser reduzidas a princípios abstratos nem se restringir a preceitos legais, uma vez que, para que tenham efeitos formativos concretos, precisam ser dominadas pelo professor e, por conseguinte, exercidas em seu trabalho na escola. Em suas palavras:

Ninguém facilita o desenvolvimento daquilo que não teve oportunidade de aprimorar em si mesmo. Ninguém promove a aprendizagem de conteúdos que não domina, a constituição de significados que não compreende nem a autonomia que não pôde construir. (MELLO, 2000, p. 102)

Esse pressuposto coloca em evidência os aspectos objetivo e subjetivo da competência, ou seja, enquanto princípio codificado na legislação, de um lado, e encarnado no indivíduo, de outro. Todavia, dada a sua relevância nesse cenário e a polissemia que encerra (LÜDKE; BOING, 2004), faz-se necessário inquirir como essa noção foi entendida pelo PEC.

A proposta básica do Programa (SÃO PAULO et al., 2003b) toma esse conceito de Perrenoud (1998, p. 208), para quem

Uma competência é um saber-mobilizar. Trata-se não de uma técnica ou de mais um saber, mas de uma capacidade de mobilizar um conjunto de recursos conhecimentos, know-how, esquemas de avaliação e de ação, ferramentas, atitudes - a fim de enfrentar com eficácia situações complexas e inéditas.

Tal noção, segundo Perrenoud (2002), possui três dimensões, sendo formada por saberes conceituais, procedimentais e atitudinais, por esquemas de ação que mobilizam esses saberes e por esquemas que não mobilizam nenhum saber. Esses esquemas, emprestados de Piaget e Bourdieu,

[...] são tudo aquilo que, em uma ação, pode ser transposto, generalizado ou diferenciado de uma situação com relação à seguinte, ou seja, tudo o que existe de comum nas diversas repetições ou aplicações da mesma ação. (PIAGET, 1973, apud PERRENOUD, 2002, p. 38)

Considerados em conjunto, formam o habitus, isto é,

[...] um pequeno grupo de esquemas que permitem gerar uma infinidade de práticas adaptadas a situações que sempre se renovam sem nunca se constituir em princípios explícitos. (BOURDIEU, 1972, apud PERRENOUD, 2002, p. 39)

Tais esquemas (ou disposições) guiam tanto a ação concreta quanto a do pensamento.

Já as competências podem ser vistas como disposições do habitus e a formação profissional, como a do professor, como um processo de socialização. A partir dessa perspectiva,

[...] não são os saberes que guiam a mobilização de outros saberes, mas aquilo que, de acordo com Piaget e Bourdieu, [denomina-se] esquemas de ação e de pensamento, os quais formam o habitus do sujeito. (PERRENOUD, 2002, p. 73) 
Nesse sentido, o caminho para desenvolvêlas, nos cursos de licenciatura, requer situações de aprendizagem que enfatizem a prática, mas sem dispensar a teoria (BRASIL, 2001), de modo que o futuro professor deve construir, enquanto aluno desse curso, as competências que vai utilizar em sua prática pedagógica, bem como as que terá que ensinar aos seus alunos quando professor, tal como preconiza o modelo de formação docente regido pela simetria invertida.

No entanto, ainda conforme esse modelo, isso não significa igualar mecanicamente as situações de aprendizagem do ensino superior com as da educação básica, pois o que se tem em vista é proporcionar ao docente em formação uma experiência de aprendizagem análoga à que seus alunos irão vivenciar. Assim,

A compreensão desse fato evidencia a necessidade de que o futuro professor experiencie, como aluno, durante todo o processo de formação, as atitudes, os modelos didáticos, capacidades e modos de organização que se pretende venham a ser concretizados nas suas práticas pedagógicas. (BRASIL, 2001, p. 39)

Supõe-se, desse ponto de vista, que o curso de licenciatura, estruturado a partir da ênfase na formação prática e da simetria invertida, faz das competências princípios de socialização que tendem a ser interiorizados sob a forma de habitus, por intermédio das relações de interdependência, diretas ou mediadas, entre formadores e alunos, nas diversas situações de aprendizagem do Programa. Nesse sentido, o que está em jogo no PEC Formação Universitária, em virtude da noção de competência adotada e da centralidade que assumiu na estruturação do seu currículo, conforme indica sua proposta básica (SÃo PAULO et al., 2003b), é a (re) estruturação do habitus do professor, em um período de tempo relativamente curto em termos de formação - apenas dois anos -, com o intuito de prepará-lo para agir em situações inéditas e, assim, dar conta dos desafios da escola contemporânea. Será isso possível ${ }^{5}$

\section{A simetria invertida às avessas}

No decorrer da execução do PEC, percebeu-se que se tornar aluna em um curso de educação continuada possibilitou, às quatro professoras acompanhadas durante a pesquisa, trazer para a reflexão certos aspectos dos ofícios docente e discente. A partir das relações e dos eventuais descompassos entre seu habitus e as situações de aprendizagem que vivenciaram, puderam pensar sobre seus próprios comportamentos como alunas em certas modalidades de ensino, as razões da conduta subversiva de alguns de seus alunos em diversas situações e determinadas incoerências entre as atividades prescritas e as realizadas pelo Programa. Observouse que esses processos foram pautados, diferentemente do que era esperado pelo Programa, por uma espécie de simetria invertida às avessas, uma vez que, em vez de ensinar em conformidade com as situações de aprendizagem que vivenciaram, as professoras afirmavam que iriam ensinar de forma distinta ou até oposta a tais experiências de formação. Para tornar esses processos mais claros, faz-se necessário problematizá-los à luz de alguns dados empíricos.

A modalidade de ensino mais questionada do PEC foi a videoconferência, principalmente em virtude do seu uso inadequado, percebido, por exemplo, na sua duração, considerada longa demais, tal como registrado por Andrade (2007). Nessa mídia interativa, o professor conferencista ficava em um estúdio de geração, equipado com câmera, microfone, computador, videocassete e câmera de documentos, que capturava sua imagem e sua voz, bem como a dos materiais utilizados durante a aula, e os transmitia em tempo real para cinco polos do Programa. Neles, as informações eram recebidas

\footnotetext{
5- A propósito desse questionamento, ver (BELLO; BUENO, 2005).
} 
por um aparelho de televisão, no qual as alunas assistiam à videoaula e, por intermédio dos equipamentos existentes no polo para o retorno de informações (câmera, microfone e câmera de documentos), entravam em contato e podiam conversar tanto com o professor-conferencista quanto com os demais colegas de outros polos.

Na maioria das vezes, a videoconferência não satisfazia às expectativas das professoras, conforme afirmaram reiteradamente, desencadeando, com efeito, diversos comportamentos, semelhantes aos de seus alunos tidos como desinteressados, tais como conversar com as colegas, fazer outras atividades, sair da sala etc. Por outro lado, possibilitavam também que tal conduta se tornasse objeto de reflexão:

[...] por que esse aí não quer fazer? Não tem tanto interesse? Então, dá pra entender um pouco como o aluno se sente diante de uma aula. Porque tinha aula que não dava. Tinham umas vídeos que dava vontade de dormir. Aí é a hora que você lembra que tem dia que você está dando aula e tem criança que está dormindo. As reações às vezes são parecidas. Aí você pensa: "Poxa, se eu estava dormindo enquanto ela estava falando, então ele está dormindo enquanto eu estou falando..." (Entrevista, Lis, 2008) ${ }^{6}$

Essa reflexão, feita a partir da condição de aluna na videoconferência, permitiu à professora, a despeito das diferenças entre os dois ambientes de ensino, relativizar o suposto desinteresse de seu aluno, ao apreciar e avaliar a possibilidade de esse comportamento estar ligado às suas próprias ações como docente e às características da sua própria aula.

A mesma professora, durante as atividades feitas em grupo no Programa, pôde comparar suas experiências discentes com suas práticas docentes, tendo em vista alguns aspectos do processo de aprendizagem inerentes à condição de aluna:

6- Os nomes utilizados são pseudônimos.
Como cada um tem um jeito de estudar, de aprender... num grupo pequeno, você vê como cada um aproveitou o curso... na situação de aluno você vê que ninguém tem o mesmo jeito [de aprender] [...] De todas as modalidades de ensino do PEC, há aquelas que eu gosto de fazer e aquelas que não... Eu gosto de ler sozinha... Hoje eu entendo uma menina que pede para fazer... Se passo a atividade em grupo, ela pede para ficar sozinha. Antes eu achava que se eram quatro alunos, tinha que ser quatro. $\mathrm{E}$ é só passando pela condição de aluno que você percebe certas coisas... A gente toma consciência. (Nota de campo/2004)

A tomada de consciência, enquanto simbolização ou conceituação de esquemas “pré-reflexivos da ação" (PERRENOUD, 2002), é uma das reações desencadeadas pela vivência simultânea dos ofícios discente e docente nos cursos de formação continuada, pois sentir as forças inerentes a cada uma dessas posições contribui para a apreensão dos sentidos de certas práticas discentes e docentes, até então opacas, o que pode levar à reorientação de determinadas formas de apreciar e agir. No caso em tela, Lis mudou sua postura sobre a organização das atividades em grupo em razão de sua experiência discente no PEC, que exigia que certas atividades fossem realizadas em grupo, chegando até a proibir a sua realização de maneira individual, tal como aconteceu no trabalho monitorado on-line. Ao perceber que preferia fazer a leitura e todas as outras atividades individualmente, do mesmo modo que uma de suas alunas, ela passou a conduzir esse tipo de atividade de maneira distinta da que vivenciou no PEC e que, até então, praticava em suas aulas. Assim, passou a autorizar sua aluna a fazer a atividade, concebida para ser em grupo, individualmente.

As tomadas de posição do professortutor, em diversas ocasiões, também foram bastante questionadas pelas alunas-professoras. Uma delas referia-se ao modo como conduzia 
os debates a respeito das leituras solicitadas pelo Programa, durante as sessões do trabalho monitorado off-line. Segundo elas, o professor-tutor não levava em consideração a opinião de algumas alunas: "ela (a tutora) não aproveita aquilo que surge no momento da aula. Uma professora trouxe um assunto, a outra trouxe outro, ela não equaciona aquilo"? Diante de tais experiências, essa aluna-professora insistia em afirmar que buscava não fazer com seus alunos aquilo que não aprovava que fizessem com ela:

Tudo que faziam pra mim, que me faziam sentir mal durante a minha vida escolar e até mesmo no PEC, alguma coisa, alguma atitude, prática, que fizesse com que eu não me sentisse bem, alguma coisa, eu não repetia com meus alunos. Eu dizia: "Eu não vou fazer com eles, se estou sentindo na pele o quanto é ruim". Eu adulta já estou achando isso ruim, imagina eles pequenos. (Entrevista, Violeta, 2008)

Assim, ao enfrentar novamente tais experiências no PEC, durante as discussões relativas às leituras conduzidas pelo tutor, Violeta pôde sentir e interpretá-las como professora na condição de aluna, a partir da simetria invertida às avessas, e agir em sua classe de maneira distinta, buscando contemplar a voz e os pontos de vista de todos os seus alunos, a fim de evitar as situações pelas quais passou.

Os conflitos existentes na turma a que pertenciam as alunas, que era composta por 15 alunas-professoras, também deram origem a processos formativos similares. Em certas ocasiões, ocorriam determinados atritos entre algumas delas. Estes, segundo os relatos, surgiram após a primeira prova e se manifestavam principalmente nas sessões de trabalho monitorado off-line, durante as discussões sobre os textos lidos. Lis, que tirou nota dez nessa avaliação, sentiu-se pessoalmente

7- Entrevista em grupo $\left(2^{\mathrm{a}}\right)$ realizada com as alunas-professoras em 2004, no âmbito do Projeto Educação à distância. Entre o presencial e 0 virtual: a formação, a leitura e a escrita dos professores. atingida por algumas colegas, que insinuaram que foi beneficiada pela orientadora da turma, a qual, além de ser responsável pela correção das provas, era coordenadora pedagógica da escola em que trabalhava.

Esses conflitos não só contribuíram para a turma se dividir, praticamente, em três grupos, como também atingiram outras alunas, fazendo com que algumas delas deixassem de participar das discussões, tanto por causa das críticas que receberam de determinadas colegas quanto por medo de receberem novas críticas, caso voltassem a participar dos debates. A respeito desse assunto, os depoimentos deixaram claro que após esses episódios houve uma diferenciação entre as alunas-professoras, gerando uma espécie de hierarquia e rivalidade entre elas e seus grupos. Além disso, evidenciaram que as discussões, com a permanência dos conflitos, deixaram de ter o potencial formativo que anteriormente tiveram.

No contexto observado, o tutor era chamado pelas alunas-professoras para mediar esses conflitos mais abertos, porém, como se tratava de adultos, ele se recusava a fazer esse papel, visto que, do seu ponto de vista, elas deveriam saber como administrar tais situações sem sua ajuda. Além disso, acreditava que a sua função no Programa não incluía a resolução de problemas dessa natureza. Diante desse impasse, uma das alunas-professoras começou a questionar a atuação do tutor, que, de certa forma, era visto no papel de professor, e, portanto, responsável por esses assuntos também.

Essa mediação está deixando a desejar. [...] Porque eu acho assim, é uma coisa pessoal que poderia ter sido trabalhada. Ninguém consegue agradar todo mundo, então não dá para eu falar: "Olha, você é o grupo mais importante”. E depois virar para o outro e dizer: "Você é o mais importante, não mais vocês”. Não dá. (Entrevista 2, Margarida, 2004)

Os questionamentos de Margarida a respeito da postura do tutor foram além. Tendo em 
vista a apresentação dos trabalhos de conclusão de curso, ocasião em que se receberia a visita da coordenadora geral de uma das universidades patrocinadoras do PEC, a aluna criticou a atitude do tutor pelo fato de ele ter estabelecido que, no momento em que a coordenadora chegasse, haveria uma interrupção na dinâmica do trabalho, independentemente de quem estivesse apresentando. Essa interrupção seria para que a aluna-professora com maior desenvoltura para expor o TCC, na avaliação do tutor, iniciasse sua apresentação:

"E aí quando ela chegar, fulana começa". Então, eu acho que não é assim. [...] se nós somos adultos e acontece, imagina com nossos alunos, que são crianças pequenas [...] Eu vi, assim, que o papel do professor..., que você é o exemplo, você tem que ter consciência disso e procurar ser muito justo. (Entrevista 3, Alunas-professoras, 2004)

Ao ver o professor como um exemplo, portanto, como um modelo de formação, essa aluna-professora passou a refletir sobre a justiça e a discriminação na relação professoraluno, a partir do modo como o tutor de sua turma conduziu a apresentação dos TCCs no PEC. Para ela, tal atitude revela certo desprezo por aqueles que não tinham tanta facilidade para expor oralmente um trabalho.

Para Carvalho (2004, p. 102),

[...] é sendo um professor justo que ensinamos o valor e o princípio da justiça aos nossos alunos, sendo respeitosos e exigindo que eles também o sejam, é que ensinamos o respeito, não como um conceito, mas como um princípio de conduta.

Pode-se afirmar que é nas relações de interdependência entre as alunas e o tutor, permeadas por práticas escolares justas, que se efetiva a formação docente orientada por esse princípio. Isso porque, de acordo com Lahire (1997, p. 64), qualquer competência aparece duas vezes ao longo da experiência do indivíduo (tanto adulto quanto criança): uma vez no plano interpsíquico e uma segunda vez, mais tarde, no plano intrapsíquico.

Porém, como o ethos da aluna (dimensão valorativa do habitus) era conflitante com o exemplo vislumbrado na postura do tutor, sua atuação como professora só poderia se dar às avessas da sua experiência formativa.

No caso da avaliação, também se pôde perceber tal processo. Se admitirmos que a concepção de Ubiratan D’Ambrósio, presente na apostila utilizada no curso, pode ser tomada como representativa da do Programa, então:

Uma avaliação adequada deve ser focalizada no aluno como indivíduo, analisando e chamando a atenção para seus erros, com muito cuidado para evitar sua humilhação perante os colegas e o seu desencanto com sua própria aprendizagem. A avaliação é o grande auxiliar do professor para orientar sua ação pedagógica. Permite motivar adequadamente os alunos e definir quais os conteúdos que melhor se adaptaram aos interesses deles. Mas isso exige que o professor deixe de cobrar retenção de conteúdos e se liberte da idéia falsa de que o programa deve ser cumprido integralmente e na ordem estabelecida. (SÃO PAUL0, 2004, p. 1161, grifo nosso)

Além disso, de acordo com a proposta básica do PEC:

Observando a simetria invertida, a avaliação é [...] uma experiência que o professor vive enquanto aluno e um conteúdo do programa com o qual ele aprenderá princípios e métodos de avaliação de aprendizagem que deverá aplicar em sua própria sala de aula. (SÃo PAULO et al., 2003b, p. 18) 
Porém, o que se nota, segundo as reflexões de uma das professoras, é a incoerência entre o modelo teórico de avaliação veiculado pelo Programa e o colocado em prática:

Esperava ser avaliada de uma forma global, sendo consideradas todas as habilidades que tenho, o conhecimento que trago, os argumentos que foram colocados para justificar e debater as discussões propostas. Percebo que fui avaliada apenas por uma prova escrita, assim como em toda a minha vida escolar. Essa primeira avaliação do PEC teve como finalidade verificar o conteúdo adquirido pelos alunos do curso tão somente. Diante dessa nova proposta de ensino, que contempla novas estratégias e instrumentos de aprendizagem e propõe uma mudança de prática pedagógica (ineficaz), é de se surpreender que a avaliação tenha sido feita de forma tão tradicional como foi. (Memórias n.2, Violeta)

Diante desse quadro, o que dizer da coerência, demandada pela simetria invertida, levada a efeito nessas ocasiões? A avaliação experienciada pelas alunas durante as provas, por exemplo, não se baseou nos pressupostos assumidos pelo PEC, chegando até a contradizêlos. No entanto, não fazia sentido para as professoras, em função do seu conjunto de disposições e da apropriação que fizeram da concepção de avaliação do Programa, ter de ensinar de acordo com o que vivenciaram na prática. Assim, para que pudessem empregar no ofício docente o que o PEC proclamava em seu discurso, a formação teria de se orientar pela simetria invertida às avessas. Mas isso seria possível? Uma resposta plausível a essa indagação exige, antes, algumas considerações.

\section{Simetria invertida, competências e formação às avessas}

A formação de professores, de acordo com Perrenoud (2002), obrigatoriamente requer a apropriação de saberes, a construção de competências e a constituição de um habitus profissional, pois o que está em jogo no trabalho docente é a capacidade de mobilizar um conjunto de recursos para lidar com os desafios presentes tanto no cotidiano escolar quanto na sala de aula. Por essa razão, o curso de licenciatura deve enfatizar, mas sem descuidar da transmissão de conteúdos, a interiorização de esquemas de ação, dentre os quais se incluem as competências, cujo domínio habilita o professor a enfrentar, com mais destreza, as situações escolares.

Para tanto, segundo Perrenoud (2002), o desenvolvimento das competências requer, de um lado, situações de aprendizagem adequadas, que operem como um treinamento intensivo capaz de criar as condições objetivas para que ocorra a interiorização e a estabilização desses esquemas de ação, e, de outro, que os formadores procurem articular os saberes com tais disposições, pois se os professores têm dificuldades em usar os saberes que adquiriram, isso se deve à incapacidade de mobilizá-los durante a ação. Sendo assim, a "formação do habitus deveria ser o projeto de toda a instituição, a obrigação de todos os formadores" (PERRENOUD, 2002, p. 83).

Como as competências atuam como a "mediação entre o aqui e agora (local de formação) e outros espaços (a sala de aula)" (PERRENOUD, 1993, p. 105), o sucesso do modelo de formação docente do país depende da qualidade e da coerência das situações de aprendizagem que o aluno experiencia durante sua formação, pois o aprendizado gerado nesse processo, de acordo com a simetria invertida, possibilitará que o futuro professor coloque em prática o que apreendeu quando atuar como docente.

No caso do PEC, considerando algumas das competências previstas na sua proposta básica, foi possível notar diversas inconsistências na estruturação de determinadas situações de aprendizagem, o que nos leva a perguntar: qual éa eficácia da experiência relacionada à construção da capacidade de se orientar "por pressupostos epistemológicos coerentes” (SÃO PAULO et 
al., 2003b, p. 10), quando se desconsidera esse princípio formativo no momento de organizar determinadas atividades, tal como ocorreu durante as avaliações? Como a postura do tutor, no que diz respeito à construção da capacidade de "solucionar problemas concretos da prática docente e da dinâmica escolar" (SÃO PAULO et al., 2003b, p. 10) e de "orientar suas escolhas e decisões metodológicas e didáticas por princípios éticos" (SÃO PAULO et al., 2003b, p. 09), poderia contribuir para a formação de tais competências, já que se costumava a se eximir da resolução dos conflitos existentes entre as alunas e, mesmo que não intencionalmente, discriminava algumas delas em certas atividades?

Essas questões evidenciam os obstáculos existentes na implantação do atual modelo de formação docente no PEC e explicitam as dificuldades do professor-tutor em colocar em prática as competências demandadas pelo Programa, o que, por sua vez, remete-nos à indagação que deu origem a estas considerações: como a simetria invertida às avessas poderia contribuir para a constituição das competências?

Pelo fato de o PEC ser, ao mesmo tempo, um curso de formação inicial e continuada, destinado a professores em exercício, o processo formativo ali desencadeado tratava mais da reestruturação do habitus profissional do que da sua construção. Permitia, ainda, que o aluno-professor, ao ocupar simultaneamente as posições discente e docente e sentir as forças sociais relativas a cada uma delas, revivesse as experiências relacionadas ao estudo e refletisse a respeito das dificuldades existentes nos processos de ensino e de aprendizagem.

Nesse sentido, como as alunas já eram professoras há vários anos e tinham valores, hábitos, esquemas e representações mais arraigadas a respeito do ofício docente, ou seja, possuíam um habitus profissional engendrado, principalmente, no curso normal de nível médio e no ambiente de trabalho na escola, o desenvolvimento de determinadas competências almejadas pelo PEC só poderia ser realizado, em alguns casos, se certos esquemas de pensamento e ação das professoras fossem desativados e/ou reestruturados. Além disso, como condições distintas de existência, ao imporem "definições diferentes do impossível, do possível, do provável ou do certo", produzem habitus dissonantes e, assim, "fazem alguns sentirem como naturais ou razoáveis práticas ou aspirações que outros sentem como impensáveis ou escandalosas" (BOURDIEU, 1984, p. 64), as alunas-professoras, ao se depararem com a formação oferecida pela PEC, tinham mais recursos para aderir, rejeitar ou assimilar seletivamente o que lhes era proporcionado.

Ademais, como as forças sob as quais as alunas-professoras estavam submetidas na posição de discente eram diferentes daquelas que as pressionavam quando se encontravam na posição de docente, as disposições ativadas em cada posição tendiam a não ser as mesmas. Esse processo, somado a certo desajustamento do habitus em relação à configuração do PEC, contribuía para a "tomada de consciência de um esquema isolado ou de uma parcela do habitus" (PERRENOUD, 2002, p. 155), ao tornar perceptíveis para as professoras vários aspectos pessoais e profissionais de suas práticas e representações que antes passavam despercebidos.

Se admitirmos, com Perrenoud (1993, p. 109), que a formação do habitus profissional se dá a partir da "interacção entre a experiência, a tomada de consciência, a discussão [e] o envolvimento em novas situações" (grifo do autor), então, podemos dizer que tais propriedades da configuração do PEC, sem que tivessem sido orquestradas para esse fim, acabaram criando um contexto capaz de estimular a autoformação presente no processo de socialização. Isso porque, sob a ótica da teoria sociológica adotada, as práticas e representações decorrem da relação dialética entre a posição que o indivíduo ocupa na configuração, o seu conjunto de saberes e esquemas de ação e a sua capacidade reflexiva, o que lhe confere uma autonomia relativa ante as pressões do contexto. 
Por essa razão, os relatos das professoras sugerem que, ao confrontar, por exemplo, o modelo de conduta do tutor, os princípios da avaliação utilizada e a pouca atratividade da videoconferência com outras referências presentes tanto em seu habitus profissional quanto no próprio discurso do Programa, acabavam, nesse processo, por criticar e reconstruir tais vivências, apropriando-se, reflexivamente, de maneira distinta ou até oposta dos modelos veiculados pela formação oferecida em tais ocasiões. Se essas análises não estiverem equivocadas, a formação baseada na simetria invertida às avessas se processaria por meio da autoformação das professoras. Esse tipo de formação daria origem, valendo-se das tensões referentes ao exercício simultâneo dos ofícios docente e discente, da formação prévia e da capacidade de reflexão, a um trabalho de apropriação das novas experiências socializadoras que poderia incitar a reestruturação de seu habitus e, assim, o domínio e/ou a consolidação das competências visadas. Eis o que foi chamado de formação às avessas.

Não obstante, corroborando estudos anteriores (BUENO, 2006; ANDRADE, 2007), as análises desenvolvidas evidenciam que o PEC valeu-se muito pouco das reflexões levadas a efeito pelas alunas-professoras, em flagrante contradição com o discurso de valorização da prática docente contido na proposta pedagógica do Programa.

Apesar de lidar com a educação continuada e, portanto, com a educação de adultos, esse aspecto não se constituiu em um princípio ou em um eixo orientador da proposta. Com isso, deixou de lado dois dados fundamentais na formação de professores que já se encontram no exercício de sua profissão: a experiência de vida e a reflexividade sobre a experiência, a despeito do discurso e do apelo à escrita de memórias. ${ }^{8} 0$ curso não valorizou suficientemente a capacidade reflexiva dos professores, ao não considerar que, enquanto

8- Críticas ao uso dessa prática em cursos voltados a grandes públicos, podem ser vistas em BUENO (2006). adultos, sua reflexão se opera no vértice de uma visão que é simultaneamente retrospectiva e prospectiva (DOMINICÉ, 1992). Olham e refletem sobre o passado, projetando o futuro. Apesar de não estimulada, foi essa capacidade que, em certa medida, permitiu às professoras lidar com as incoerências do Programa e não se enquadrar plenamente no modelo de formação docente proposto, orientado pela simetria invertida.

Essa inversão foi também resultante de uma concepção equivocada de prática adotada pelo Programa. Com efeito, a proposta pedagógica do PEC permitiu entrever que a prática das professoras era remetida apenas ao que realizavam em suas salas de aulas como docentes, e não ao que praticavam nas salas presenciais e virtuais do Programa como alunas. Trata-se, assim, de uma concepção ambígua sobre o que é ser professor e ser professor em formação (BUENO, 2010), aspecto que, a nosso ver, contribuiu para gerar e/ou acentuar as demais ambiguidades do Programa.

Diante desse quadro, os impasses do modelo de formação docente pautado pelas DCNFP e implementado pelo PEC, principalmente em virtude da coerência exigida pela simetria invertida entre o que se faz na formação e o que se espera do professor na docência, são evidentes. Nesse sentido, se os cursos de licenciatura não considerarem devidamente a capacidade de reflexão e as experiências dos alunos, o domínio das competências por todos os formadores de professores e a organização das situações de aprendizagem pelos mesmos princípios que regem a organização da educação básica, provavelmente não serão criadas as condições necessárias para a construção e/ ou reestruturação das disposições relativas às competências estabelecidas pelo modelo de formação vigente, o que terminaria por comprometer a formação do habitus profissional visado e a esperada sintonia fina entre esses dois níveis de ensino. 


\section{Referências}

ANDRADE, Andressa de. Uso(s) das novas tecnologias em um programa de formação de professores: possibilidades, controle e apropriações. Dissertação (Mestrado em educação) — Faculdade de Educação, Universidade de São Paulo, São Paulo, 2007.

BELLO, Isabel Melero; BUENO, Belmira Oliveira. É possível mudar o habitus docente? Uma análise sobre o PEC Formação Universitária. In: ENCONTRO DE PESQUISA DA EDUCAÇÃO DA REGIÃO SUDESTE, 7., 2005, Belo Horizonte. Anais da VII reunião anual da ANPEd - Sudeste. Belo Horizonte: ANPEd, 2005.

BOURDIEU, Pierre. Esboço de uma teoria da prática. In: ORTIZ, Renato (Org.). Pierre Bourdieu. São Paulo: Ática, 1984.

Razões práticas: sobre a teoria da ação. Campinas: Papirus, 2004.

BRASIL. Ministério da Educação. Proposta de diretrizes para a formação inicial de professores da educação básica em cursos de nível superior. Brasília: MEC/SEB, maio 2000.

Conselho Nacional de Educação. Diretrizes nacionais para a formação de professores da educação básica, em nível superior, curso de licenciatura, de graduação plena. Parecer CNE/CES 09. Brasília: MEC/SEB, de 08 de maio de 2001.

Conselho Nacional de Educação. Institui as Diretrizes Curriculares Nacionais para a Formação de Professores da Educação Básica, em nível superior, curso de licenciatura, de graduação plena. Resolução CNE/CP 01. Brasília: MEC/SEB, 18 fev. 2002.

BUENO, Belmira Oliveira. Educação à distância. Entre o presencial e o virtual: a formação, a leitura e a escrita dos professores. São Paulo: USP/FE, 2003. Projeto para bolsa de produtividade em pesquisa. (Processo n. 500755/2003-5)

É possível reinventar os professores? A escrita de memórias em um curso especial de formação de professores. In: $\overline{S O U Z A}$, Eliseu Clementino de; ABRAHÃO, Maria Helena Menna Barreto. Tempos, narrativas e ficções: a invenção de si. Porto Alegre/Salvador: EDIPUCRS/EDUNEB, 2006.

Não identidades ou identidades emergentes? Os programas especiais e a produção de novas narrativas sobre a formação docente. In: DALBEN, Ângela Imaculada Loureiro de Freitas et al. Didática e prática de ensino. Belo Horizonte: Autêntica, 2010.

; OLIVEIRA, Adolfo Samuel. La educación a distancia en otro registro: usos y apropiaciones de tecnologías en la formación de profesores. Universitas Psychologica, Bogotá, v. 7, n. 3, p. 823-836, dic. 2008.

CARVALHO, José Sérgio Fonseca de. Podem a ética e a cidadania serem ensinadas? In: (Org.) Educação, cidadania e

direitos humanos. Petrópolis: Vozes, 2004.

DOMINICÉ, Pierre. L’histoire de vie comme processus de formation. Paris: L'Harmattan, 1992.

ELIAS, Norbert.0 processo civilizador. v. I. Rio de Janeiro: Zahar, 1994.

Introdução à sociologia. Lisboa: Edições 70, 2005.

LAHIRE, Bernard. 0 sucesso escolar em meios populares: as razões do improvável. São Paulo: Ática, 1997.

Homem plural: os determinantes da ação. Petrópolis: Vozes. 2002.

LÜDKE, Menga; BOING, Luiz Alberto A. Caminhos da profissão e da profissionalidade docentes. Educação \& Sociedade, Campinas, v. 25, n. 89, p. 1159-1180, 2004.

MELLO, Guiomar Namo de. Formação inicial de professores para a educação básica: uma (re)visão radical. São Paulo em Perspectiva, São Paulo, v. 14, n. 1, p. 98-110, 2000.

OLIVEIRA, Adolfo Samuel de. Quando o professor se torna aluno: tensões, desafios e potencialidades da formação em serviço. Dissertação (Mestrado em Educação) — Faculdade de Educação, Universidade de São Paulo, São Paulo, 2009.

PERRENOUD, Philippe. Práticas pedagógicas, profissão docente e formação: perspectivas sociológicas. Lisboa: Dom Quixote, 1993. 
PERRENOUD, Philippe. Formação contínua e obrigatoriedade de competências na profissão de professor. In: CONHOLATO, Maria Conceição, et.al. Sistemas de avaliação educacional. São Paulo: FDE, 1998. (Idéias; 30). p. 205-248.

. Prática reflexiva no ofício do professor. Porto Alegre: Artmed, 2002.

SÃO PAULO (Estado) et al. PEC formação universitária municípios. Manual do aluno. São Paulo, 2003a.

PEC Formação Universitária Municípios. Proposta básica. São Paulo, 2003b.

. SECRETARIA DA EDUCAÇÃO. PEC Formação Universitária Municípios. Matemática. Módulo 2, Tema 5. São Paulo, 2004.

SETTON, Maria da Graça Jacintho. A teoria do habitus em Pierre Bourdieu: uma leitura contemporânea. Revista Brasileira de Educação, Rio de Janeiro, n. 20, p. 60-70, mai./jun./jul./ago. 2002a.

. Família, escola e mídia: um campo com novas configurações. Educação e Pesquisa, São Paulo, v. 28, n. 1, p. 107-116, jan./jun. 2002b.

Educação e cultura no Brasil contemporâneo. Disponivel em: <http://www.anped.org.br/reunioes/28/textos/gt16/ gt16111int.rtf>. Acesso em: 05 set. 2007.

. A socialização como fato social total: notas introdutórias sobre a teoria do habitus. Revista Brasileira de Educação, Rio de Janeiro, v. 14, n. 41, p. 296-307, 2009.

Recebido em: 22.06.2012

Aprovado em: 05.02.2013

Adolfo Samuel de Oliveira é sociólogo pela Faculdade de Filosofia, Letras e Ciências Humanas da Universidade de São Paulo (USP) e doutorando em Educação, com bolsa CAPES, na Faculdade de Educação da USP.

Belmira Oliveira Bueno é professora titular da Faculdade de Educação da Universidade de São Paulo (USP) e pesquisadora do CNPq. Coordena, desde 2009, o Projeto Temático FAPESP Programas Especiais de Formação de Professores, Educação a Distância e Escolarização: pesquisas sobre novos modelos de formação em serviço, ao qual a presente pesquisa se vincula. 